\title{
Carbon monoxide yield of cigarettes and its relation to cardiorespiratory disease
}

\author{
COLIN BORLAND, ANDREW CHAMBERLAIN, TIM HIGENBOTTAM, MARTIN SHIPLEY, \\ GEOFFREY ROSE
}

\begin{abstract}
Estimates of the carbon monoxide yield of their cigarettes have been obtained for 4910 smokers ( $68 \%$ of all smokers) in the Whitehall study of men aged 40 to 64 . In the 10 years after examination 635 men died. When men smoking cigarettes with high carbon monoxide yield were compared with those smoking cigarettes with a low yield, and after adjusting for age, employment grade, amount smoked, and tar yield, the risk of death was $32 \%$ lower for coronary heart disease, $\mathbf{4 9} \%$ higher for lung cancer, and $10 \%$ lower for total mortality; these differences were not statistically significant. Among men who said that they inhaled the risk of fatal coronary heart disease was $51 \%$ lower in the high carbon monoxide group $(p<0.01)$, while the risk of lung cancer was $75 \%$ higher.

These results provide no evidence that a smoker can reduce his risk of death by smoking a brand with a low carbon monoxide yield; he might even increase it. The complex interactions between characteristics of the smoker, smoking behaviour, constituents of tobacco smoke, and health are again demonstrated.
\end{abstract}

\footnotetext{
Respiratory Physiology Department, Addenbrooke's Hospital, Cambridge CB2 2QQ

COLIN BORLAND, MRCP, research fellow

ANDREW CHAMBERLAIN, MSC, research assistant

TIM HIGENBOTTAM, MD, consultant physician

Department of Epidemiology, London School of Hygiene and Tropical Medicine, London WC1E 7HT

MARTIN SHIPLEY, MSC, research fellow

GEOFFREY ROSE, DM, professor of epidemiology

Correspondence to: Professor G Rose.
}

\section{Introduction}

The search for a less hazardous cigarette has depended on identifying suspected harmful components of tobacco smoke and then reducing their concentrations. Initial interest centred on tar, and in the United Kingdom between 1960 and 1980 the sales weighted average yield for tar in manufactured cigarettes fell from 31 to $16 \mathrm{mg}^{1}$; this decline is tending to flatten out. Concern is now moving to carbon monoxide, because of its suspected relation to cardiovascular disease ${ }^{2}$ and perhaps also to lung disease $\mathrm{e}^{3-5}$; over a similar period its yield fell only from 21 to $16.5 \mathrm{mg}$. There is growing pressure both on manufacturers to reduce the average carbon monoxide yield and on the public to prefer lower yield brands. Nevertheless, there is no direct evidence on the health consequences of such a policy. The experience of the Whitehall study is relevant. ${ }^{6}$ ?

\section{Methods}

In 1967-9 the Whitehall study examined 18403 civil servants aged 40 to 64 . Each completed a questionnaire, which included details of current cigarette consumption and usual cigarette brand, and underwent recordings with a dry wedge spirometer. The prevalence of coronary heart disease at initial examination was assessed by the presence of "angina" and "possible infarction," as defined by the standard questionnaire. ${ }^{6}$ Electrocardiographic evidence of ischaemia was defined by Minnesota codes $1 \cdot 1-3,4 \cdot 1-4,5 \cdot 1-3$, or $7 \cdot 1$.

The tar and nicotine yields of cigarette brands were known from contemporary analyses performed by the industry, but no such data were available for carbon monoxide. Recently, however, the Government Chemist has analysed old packs of cigarettes, and from this source the carbon monoxide yields were available for the cigarettes smoked by $68 \%$ of the cigarette smokers in the study. ${ }^{8}$ The remainder smoked hand rolled cigarettes or less popular brands. Contemporary analysis and the recent reanalysis for both tar and nicotine showed excellent correlation $(r=0.90$ for tar and 0.86 for nicotine; $n=22)$ and the mean differences (results of recent reanalysis minus those of contemporary analysis) were small: +0.9 (SD 0.03) $\mathrm{mg}$ for tar and -0.08 (SD 0.003$) \mathrm{mg}$ for nicotine. This implies that for these constituents the old packs of cigarettes were representative and deterioration in storage was negligible. No such validation was possible for the carbon monoxide estimates. 
The study population was divided into three categories according to the carbon monoxide values, and analysis was based on the method of Nelder and Wedderburn. ${ }^{9}$ Mortality rates, odds ratios, and $\chi^{2}$ tests for trend were calculated with the fitted models.

\section{Results and comment}

Table I compares the smokers now analysed with those smokers in the original Whitehall study who were excluded because the carbon monoxide values of their cigarettes were not known. The present study group has a deficit of men from lower employment grades, chiefly because they were the main users of hand rolled cigarettes. During the 10 years of follow up 635 men in the present study died. The underlying cause was given as coronary heart disease (ICD 410-414) in 255 and lung cancer (ICD 162) in 90

Table II shows the relation of daily cigarette consumption to carbon monoxide yield. Higher yield brands were more popular among light smokers, $16^{\circ}$ of whom chose a brand yielding more than $20 \mathrm{mg}$, compared with only $11 \%$ of heavy smokers. Furthermore, men who were in the lower employment grades or who reported that they inhaled tended to smoke low carbon monoxide brands

The figure shows the dispersion of carbon monoxide yields and their relation to tar yields. The correlation was low $(+0.05)$ and not

TABLE I-Comparison of smokers with known and unknown carbon monoxide yields of cigarettes

\begin{tabular}{|c|c|c|}
\hline & $\begin{array}{c}\text { Known } \\
\text { carbon monoxide } \\
(n=4910)\end{array}$ & $\begin{array}{l}\text { Unknown } \\
\text { carbon monoxide } \\
(\mathrm{n}=2360)\end{array}$ \\
\hline 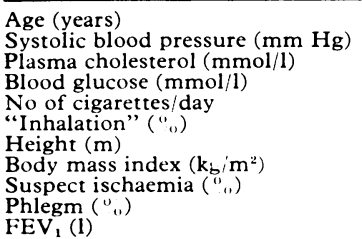 & $\begin{array}{c}51 \cdot 7 \\
134 \cdot 7 \\
5 \cdot 10 \\
1.95 \\
16.9 \\
80.0 \\
1.75 \\
24.4 \\
16.5 \\
34 \cdot 1 \\
3.01\end{array}$ & $\begin{array}{c}52 \cdot 1 \\
135.4 \\
5 \cdot 12 \\
1.95 \\
14.3 \\
77 \cdot 6 \\
1.75 \\
24.3 \\
16 \cdot 1 \\
33.9 \\
3.01\end{array}$ \\
\hline
\end{tabular}

Some means may be based on fewer subjects because of missing values. Al Some means may be based on fewer subjects because

TABLE II-Percentage distribution (and numbers) of 4910 cigarette smoker according to number of cigarettes smoked and carbon monoxide yield

\begin{tabular}{ccccc}
\hline \multirow{2}{*}{ Cigarettes smoked per day } & \multicolumn{4}{c}{ Carbon monoxide yield: } \\
\cline { 2 - 5 } & $\leqslant 18 \mathrm{mg}$ & $>18-20 \mathrm{mg}$ & $>20 \mathrm{mg}$ & Total \\
\hline $1-9$ & $24 \cdot 8(237)$ & $58 \cdot 7(560)$ & $16 \cdot 5(157)$ & $100 \cdot 0(954)$ \\
$10-19$ & $30 \cdot 2(536)$ & $57 \cdot 0(1012)$ & $12 \cdot 7(226)$ & $99 \cdot 9(1774)$ \\
$\geqslant 20$ & $35 \cdot 6(776)$ & $53 \cdot 2(1161)$ & $11 \cdot 2(245)$ & $100 \cdot 0(2182)$ \\
& & & & \\
\end{tabular}

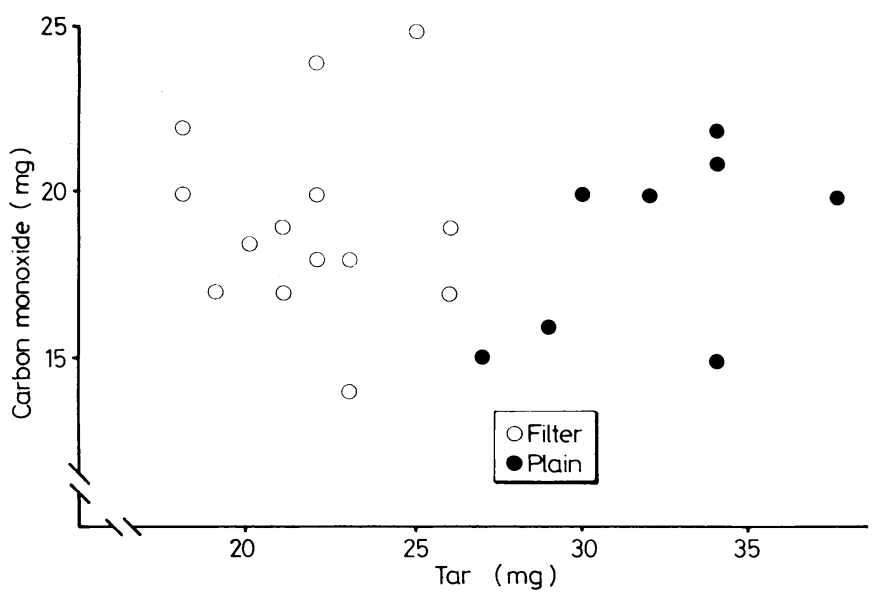

Relation in analysed brands between tar yield (manufacturers' contemporary estimates) and carbon monoxide yield (recent estimates on reconstituted cigarettes). significant. There was also essentially no association between carbon monoxide and nicotine yields $(\mathbf{r}-+0.01)$

Table III shows the relations between carbon monoxide yield and various measures of smoking related disease, standardised for age and employment grade. None of the trends are significant at the $5 \%$ level.

TABLE III-Prevalence of suspected myocardial ischaemia and 10 year mortality rates by carbon monoxide yield of cigarettes

\begin{tabular}{|c|c|c|c|c|}
\hline \multirow[b]{2}{*}{ Outcome } & \multicolumn{3}{|c|}{ Carbon monoxide yield: } & \multirow{2}{*}{$\begin{array}{l}\chi^{2} \text { for } \\
\text { linear } \\
\text { trend* }\end{array}$} \\
\hline & $\begin{array}{l}\leqslant 18 \mathrm{mg} \\
(\mathrm{n}=1535)\end{array}$ & $\begin{array}{l}18-20 \mathrm{mg} \\
(\mathrm{n}=2709)\end{array}$ & $\begin{array}{r}20 \mathrm{mg} \\
(\mathrm{n}=626)\end{array}$ & \\
\hline Prevalence of suspected & $15 \cdot 6$ & $16 \cdot 4$ & $18 \cdot 0$ & $1 \cdot 78$ \\
\hline $\begin{array}{l}10 \text { year CHD mortality (".) } \\
\text { Total }\end{array}$ & $5 \cdot 39$ & 4.99 & 3.59 & 2.55 \\
\hline With ischaemia & $10 \cdot 31$ & $9 \cdot 45$ & $8 \cdot 32$ & $0 \cdot 39$ \\
\hline Without ischaemia & 4.49 & $4 \cdot 01$ & $2 \cdot 47$ & $3 \cdot 20$ \\
\hline $\begin{array}{l}\text { Prevalence of phlegm }\left({ }^{\circ}{ }_{1}\right) \\
10 \text { year lung cancer }\end{array}$ & $33 \cdot 2$ & $34 \cdot 0$ & 33.9 & 0.22 \\
\hline $\begin{array}{l}10 \text { year lung cancer } \\
\text { mortality (".,) } \\
10 \text { year other non } \mathrm{CHD}\end{array}$ & $1 \cdot 39$ & 1.88 & $1 \cdot 90$ & 1.38 \\
\hline $\begin{array}{l}10 \text { year other non CHD } \\
\text { mortality ("1.) }\end{array}$ & $5 \cdot 46$ & $5 \cdot 93$ & $5 \cdot 32$ & 0.03 \\
\hline $\begin{array}{l}10 \text { year all causes } \\
\text { mortality ("..) }\end{array}$ & 12.21 & $12 \cdot 81$ & $10 \cdot 80$ & 0.22 \\
\hline
\end{tabular}

$\mathrm{CHD}=$ Coronary heart disease.

All rates are standardised for age and employment grade to the total Whitehall study All rates are

*Requires $*$ (ldf) $\geqslant 3.84$ for $p \cdot 0.05$

Table includes only subjects with known ischaemia status.

The prevalence of suspected coronary heart disease tended to increase as carbon monoxide yield increased. The trend for mortality on the other hand, was in the opposite direction, the strongest negative trend being among men free of suspected myocardial ischaemia (symptoms or electrocardiographic changes). Carbon monoxide yield was not evidently associated with the production of phlegm or with other causes of death.

Table IV summarises the mortality relations in the form of odds ratios, after controlling for age, employment grade, daily number of cigarettes, and tar yield. All the models gave goodness of fit statistics indicating adequate fit to the observed data. The $95 \%$ confidence intervals all include unity, so that again no significant effects have emerged. Nevertheless, the "best estimates" that emerge from these data are that smoking the high carbon monoxide cigarette is associated with a $32^{\circ}{ }^{\circ}$ reduction in the risk of death from coronary heart disease and a $49^{\circ}$, increase in the risk of death from lung cancer. The association with total and other mortality is again irregular.

TABLE IV-Odds ratios (and 95\% confidence intervals) for various causes of 10 year mortality by carbon monoxide yield of cigarettes

\begin{tabular}{lccc}
\hline \multirow{2}{*}{ Outcome } & \multicolumn{3}{c}{ Carbon monoxide yield: } \\
\cline { 2 - 4 } & $\leqslant 18 \mathrm{mg}$ & $18-20 \mathrm{mg}$ & $20 \mathrm{mg}$ \\
\hline CHD & 1.00 & $0.99(0.75 ; 1.32)$ & $0.68(0.42 ; 1.10)$ \\
Lung cancer & 1.00 & $1.50(0.91 ; 2.46)$ & $1.49(0.72 ; 3.10)$ \\
Other non-CHD & 1.00 & $1.12(0.85 ; 1.47)$ & $0.99(0.65 ; 1.51)$ \\
All causes & 1.00 & $1.12(0.92 ; 1.37)$ & $0.90(0.66 ; 1.22)$ \\
\hline
\end{tabular}

$\mathrm{CHD}=$ Coronary heart disease

Chictes/day, and tar yield.

Any effect of carbon monoxide on the cardiovascular system might be expected to be seen more clearly among men who inhale. ${ }^{7}$ Table $\mathrm{V}$ analyses coronary mortality (adjusted for age and employment grade) according to reported inhalation habit. A striking result emerges: there is a strong and highly significant inverse relationship between carbon monoxide yield and mortality rate among self reported inhalers, the rate in the low carbon monoxide group being more than twice as high as in the high carbon monoxide group. Among those who denied inhaling the opposite was seen, high carbon monoxide smokers having the highest mortality (but not significantly so at the $5^{\circ}$, level).

A similar analysis for lung cancer mortality showed that among men who reported inhaling the risk of lung cancer was $75 \%$ higher in the high carbon monoxide group, though the trend was not significant. In non-inhalers, however, the highest rates were in the low carbon monoxide group, but the numbers were small. 
TABLE V-10 year mortality from coronary heart disease by carbon monoxide yield of cigarettes and reported inhalation habit. Results are percentage mortality (and numbers of deaths)

\begin{tabular}{ccccc}
\hline \multirow{2}{*}{ Reported inhalation } & \multicolumn{3}{c}{ Carbon monoxide yield: } & \multirow{2}{*}{$\begin{array}{c}\chi^{2} \text { for } \\
\text { linear } \\
\text { trend }\end{array}$} \\
\cline { 2 - 4 } & $\leqslant 18 \mathrm{mg}$ & $>18-20 \mathrm{mg}$ & $20 \mathrm{mg}$ & \\
\hline Yes & $6.12(79)$ & $4.98(107)$ & $3.01(14)$ & 6.83 \\
No & $3.03(11)$ & $5.55(36)$ & $5.59(8)$ & 2.52 \\
\hline
\end{tabular}

All rates are standardised for age and grade of employment to the total Whitehall study population.

Require $\chi^{2}(\mathrm{ldf}) \geqslant 3.84$ for $\mathrm{p}<0.05 ; z^{2} \geqslant 6.63$ for $p<0.01$

There was a highly significant positive association between $\mathrm{FEV}_{1}$ and carbon monoxide yield of cigarettes (table VI). Adjustment for amount smoked, tar yield, and employment grade halved the magnitude of the trend but it still remained consistent.

TABLE VI-Mean values of $F E V_{1}$ (litres) in relation to carbon monoxide yield, adjusted for (a) age only, and (b) age, number of cigarettes, employment grade, tar. Figures in parentheses are standard errors

\begin{tabular}{lccc}
\hline \multirow{2}{*}{ Adjustment } & \multicolumn{3}{c}{ Carbon monoxide yield: } \\
\cline { 2 - 4 } & $\leqslant 18 \mathrm{mg}$ & $>18-20 \mathrm{mg}$ & $>20 \mathrm{mg}$ \\
\hline (a) Age only & $2.96(0.015)$ & $3.04(0.012)$ & $3.10(0.024)$ \\
(b) All factors & $2.97(0.015)$ & $3.01(0.011)$ & $3.04(0.023)$ \\
\hline
\end{tabular}

\section{Discussion}

We still do not know which components of cigarette smoke are responsible for its associated cardiovascular hazard. Carbon monoxide in high concentration is a known poison and it might be argued that it should be reduced as much as possible. Nevertheless, the cardiovascular effects of long term low level exposure remain uncertain. Astrup reported that exposure to carbon monoxide produced atheroma in rabbits fed cholesterol ${ }^{10}$; but this may be a poor model for human disease. ${ }^{11}$ An association between the prevalence of arterial disease and carboxyhaemoglobin may simply indicate that the latter is a better index of exposure to tobacco smoke than reported smoking history. ${ }^{12}$

Acute exposure to carbon monoxide could impair oxygen transport to the myocardium as a result of the formation of carboxyhaemoglobin. This may explain why when men with established coronary heart disease are acutely exposed to carbon monoxide they experience a reduction in exercise tolerance. ${ }^{13}$ It might also explain our observed association between higher carbon monoxide yields of cigarettes and symptoms of ischaemia. Nevertheless, long term low level exposure may improve oxygen transport by causing a rise in the haemoglobin concentration, ${ }^{14}$ and tissue adaptation may facilitate an increase of oxygen uptake. ${ }^{15}$ Interestingly, a recent case control study ${ }^{16}$ found no evidence that the risk of myocardial infarction in smokers is related to the carbon monoxide yield of their cigarettes.

In our analysis it was possible to separate the effects of carbon monoxide yieid from the effects of tar and nicotine, because the yields of these constituents were not correlated at the time of the study (figure). Carbon monoxide yield may exert a weak effect on the prevalence of clinical evidence of established coronary heart disease (angina, history of possible myocardial infarction, and ischaemic type electrocardiographic changes). Quite the reverse is seen for death from coronary heart disease, when smokers of high carbon monoxide cigarettes have $32 \%$ less risk of dying than smokers of low yield cigarettes. Furthermore, this negative effect is increased and very significant among self reported inhalers. This contrasts with our earlier observations on tar, where among inhalers the high $\operatorname{tar}$ and nicotine group had a greater mortality risk than the low tar and nicotine group. ${ }^{7}$ The inverse carbon monoxide associated risk is particularly affected by smoking behaviour (as measured by self reported inhalation), perhaps by influencing the site and degree of absorption of the constituents of smoke.

Long term exposure of the lungs to carbon monoxide may contribute to the development of lung disease. Acute poisoning with carbon monoxide may cause alveolar shadowing on chest radiographs, suggesting interstitial changes ${ }^{3}$ or alterations in alveolar permeability ${ }^{4}$; but the relation of these acute changes to the development of chronic airways disease or emphysema, or both, is unknown. In our study smokers of high carbon monoxide cigarettes had the best values of $\mathrm{FEV}_{1}$, which suggests that carbon monoxide is not a major factor in chronic obstructive bronchitis or emphysema.

It has been suggested that carbon monoxide yield may predict the yield of other gases such as acrolein and hydrogen cyanide, ${ }^{17}$ known to be toxic to pulmonary epithelium. ${ }^{18}$ Nevertheless, it is unwise to take the health correlates of carbon monoxide yield as a guide to the effects of other gases until we know more about how their concentrations vary together in different brands.

The estimated risk of death from lung cancer was almost $50 \%$ greater in the group smoking high yield cigarettes, though this increase was seen only among inhalers. Possibly carbon monoxide or some associated gas phase component is responsible, although the suspected carcinogens in cigarette smoke are believed to be principally in the tar. ${ }^{19}$

Wald has recently been unable to find any clear association between smokers' estimated carbon monoxide retention and the carbon monoxide yield of their cigarettes. ${ }^{20}$ Though there may be other explanations, ${ }^{21}$ his finding raises the possibility that carbon monoxide may have mental effects, which, like nicotine, influence inhalation and hence carboxyhaemoglobin concentrations. Such compensatory behaviour might perhaps account for the increased coronary mortality among inhaling smokers of low carbon monoxide brands.

These results provide no evidence to support the view that the smoker can reduce his risk by changing to a brand with a lower yield of carbon monoxide; indeed, total mortality was higher in smokers of low yield brands. The complexity of smoke chemistry, the variability of smoking habits, the arbitrary choice of cigarette brand, and our ignorance of the mechanisms responsible for consequent damage to health combine to make it difficult to predict the effects on health of manipulating the constitution of cigarette smoke.

C Borland is supported by a grant from the East Anglian Regional Health Authority, the BMA Edith Walsh Award, and the Mason Medical Research Fund. A Chamberlain is supported by a grant from Leo Research Foundation.

\section{References}

1 Fairweather FA, Carmichael IA, Phillips GF. Changes in the tar, nicotine and carbon monoxide yields of cigarettes sold in the United Kingdom. Health Trends $1981 ; 13: 77-82$.

${ }^{2}$ Schievelbein H. Evaluation of the role of carbon monoxide and nicotine in the pathogenesis of arteriosclerosis and cardiovascular disease. Preventive Medicine 1979;8:379-89.

${ }^{3}$ Sone S, Higashihara $\mathrm{T}$, Kotake $\mathrm{K}$, et al. Pulmonary manifestations in acute carbon monoxide poisoning. $A 7 R$ 1974;120:865-71.

${ }^{4}$ Fein A, Grossman RF, Jones JG, Hoeffel J, McKay D. Carbon monoxide effect on alveolar permeability. Chest 1980;78:726-31.

${ }^{5}$ Calverley PMA, Leggett RJE, Flenley DC. Carbon monoxide and exercise tolerance in chronic bronchitis and emphysema. $\mathrm{Br} \mathrm{Med} \mathcal{F}$ $1981 ; \mathbf{2 8 3}: 878-80$.

${ }^{6}$ Reid DD, Brett GZ, Hamilton PJS, Jarrett RJ, Keen H, Rose G. Cardiorespiratory disease among middle-aged male civil servants. Lancet $1974 ; \mathrm{i}: 469-73$.

${ }^{7}$ Higenbottam T, Shipley MJ, Rose G. Cigarettes, lung cancer, and coronary heart disease: the effects of inhalation and tar yield. $\mathcal{F}$ Epidemiol Community Health 1982;36:113-7.

${ }^{8}$ Wald N, Doll R, Copeland G. Trends in tar, nicotine, and carbon monoxide yields of UK cigarettes manufactured since 1934. $\mathrm{Br} \mathrm{Med} \mathrm{F}$ 1981 ;282 : 763-6.

${ }^{9}$ Nelder JA, Wedderburn RWM. Generalised linear models. Fournal of the Royal Statistical Society $A$ 1972;135:370-84. 
${ }^{10}$ Astrup P. Some physiological and pathological effects of moderate carbon monoxide exposure. $\mathrm{Br}$ Med $\mathcal{F}$ 1972; iv:447-52.

11 Mitchell JRA, Schwartz CJ. Arterial disease. Oxford: Blackwell Scientific, 1965.

12 Wald NJ, Howard S, Smith PG, Kjeldsen K. Association between atherosclerotic diseases and carboxyhaemoglobin levels in tobacco smokers. Br Med f 1973; :761-5.

${ }^{13}$ Anderson EW, Alderman RJ, Strauch JM, Fortuin NJ, Knelson JH. Effect of low level CO exposure on onset and duration of angina pectoris. Ann Intern Med 1979;79:46-50.

14 Smith JR, Landaw SA. Smokers polycythaemia. N Engl f Med 1978; 298:6-10.

15 Wagner JA, Horvath SM, Andrew GM, et al. Hypoxia, smoking history and exercise. Aviat Space Environ Med 1978;49:785-91.

${ }^{16}$ Kaufman DW, Helmrich SP, Rosenberg L, Miettinen OS, Shapiro S. Nicotine and carbon monoxide content of cigarette smoke and the risk of myocardial infarction in young men. $N$ Engl 7 Med 1983;308: 409-13.

17 Young JC, Robinson JC, Rickert WS. How good are the numbers for cigarette tar at predicting deliveries of carbon monoxide, hydrogen cyanide, and acrolein ? F Toxicol Environ Health 1981; 7:801-8.

is Kensler CJ, Battista S. Chemical and physical factors affecting mammalian ciliary activity. Am Rev Respir Dis 1966;93:93-102.

19 Hoffman D, Wynder EL. A study of tobacco carcinogenesis XI tumour indicators, tumour accelerators and tumour promoting activity of condensate factors. Cancer $1971 ; 27$ (4):848-64.

20 Wald NJ, Boreham J, Bailey A. Risk of myocardial infarction in relation to nicotine and carbon monoxide yields of cigarettes. Thorax (in press)

$\because 1$ Burgess JH. Pulmonary diffusing capacity (for carbon monoxide) in disorders of the pulmonary circulation. Circulation 1974;49:541 50.

(Accepted 8 November 1983)

\title{
Chronic otitis media with effusion (glue ear) and adenotonsillectomy: prospective randomised controlled study
}

\author{
A RICHARD MAW
}

\begin{abstract}
A prospective study was conducted of the effects of adenoidectomy and adenotonsillectomy on established otitis media with effusion unresponsive to medical treatment. The operations were performed at random with a controlled no surgery group on a cohort of 103 children with the condition and the results assessed six weeks, three months, six months, nine months, and one year later. After adenoidectomy the rate of resolution of the condition increased from $39 \%$ at six weeks to $72 \%$ at one year; and after adenotonsillectomy the rate increased from $59 \%$ at six weeks to $62 \%$ at one year. In the no surgery group the rate increased from $16 \%$ at six weeks to $26 \%$ at one year. Compared with the no surgery group the effect of adenoidectomy alone at one year was highly significant $(p<0.001)$, and similarly the effect of adenotonsillectomy was significant $(p<0.01)$. There was, however, no increased benefit from the addition of tonsillectomy compared with adenoidectomy alone. Thus there was resolution of $36-46 \%$ of chronic effusions as a result of adenoidectomy.
\end{abstract}

\section{Introduction}

Otitis media with effusion, a term synonymous with chronic non-suppurative otitis media, secretory otitis media, serous otitis media, and glue ear, is one of the commonest chronic otological conditions of childhood. It results from alteration of the mucociliary system within the middle ear cleft and is frequently caused by malfunction of the eustachian tube. Serous or mucoid fluid accumulates within the cleft where there is a negative pres-

Bristol Royal Infirmary, Bristol BS2 8HW

A RICHARD MAW, MB, FRCs, consultant otolaryngologist sure. It is especially prevalent in children with cleft palate and frequently occurs in association with upper respiratory tract infection and generalised disorders such as allergic rhinitis, fibrocystic disease, and ultrastructural cilial abnormalities of the mucosa of the respiratory tract. The condition presents in children as hearing loss, which may be overt or covert, presenting as educational or behavioural problems. Often, however, the hearing loss is first detected on routine screening examinations. Occasionally attention is drawn to it by frequent episodes of otalgia, which signify an acute episode of suppurative otitis media superadded to a middle ear effusion, and very occasionally presentation is with complications such as continuous otorrhoea secondary to perforation.

Treatment varies widely and is directed to the ears in the form of myringotomy and aspiration with or without insertion of a grommet; to the nose and sinuses by eradication of infection and control of allergy; and to the postnasal space and oropharynx in the form of adenoidectomy and tonsillectomy. It is removal of the adenoids and tonsils which is mainly responsible for the morbidity and mortality attached to the treatment of chronic otitis media with effusion. The main reasons postulated for adenoidectomy as a means of treatment and prevention of recurrence have centred on the size of the adenoids and their role as a focus for ascending eustachian tube infection. In addition, they are thought to alter nasopharyngeal pressure relations. The potential source of infection from the tonsils is similarly implicated. Removal of the tonsils, however, is often additionally advised with adenoidectomy on grounds which on their own merit might not prove valid for tonsillectomy.

Arguments for ${ }^{1-3}$ and against ${ }^{4-8}$ adenoidectomy and adenotonsillectomy for all types of disease of the middle ear have been discussed and reported at length in papers and symposia world wide. ${ }^{9-12}$ Nevertheless, given the large numbers of these operations performed for this condition, it is remarkable that so few studies have been carried out to substantiate their efficacy. Evidently the long held belief that adenoidectomy relieves recurrent acute suppurative otitis media has been extrapolated, as yet without convincing supportive evidence as grounds for the management of otitis media with effusion. The present study began prospectively in September 1979 with the specific object to evaluate randomly the effect of adenoidectomy and adeno- 